\title{
A Look at the Relationship between the Large-Scale Tropospheric Static Stability and the Tropical Cyclone Maximum Intensity
}

\author{
ALEXANDRIA DOWNS AND CHANH KIEU \\ Department of Earth and Atmospheric Sciences, Indiana University, Bloomington, Indiana
}

(Manuscript received 25 April 2019, in final form 18 October 2019)

\begin{abstract}
Various modeling and observational studies have suggested that tropical cyclone (TC) intensity tends to increase in the future due to projected warmer sea surface temperature (SST). This study examines the effects of the tropospheric stratification that could potentially offset the direct increase of TC intensity associated with the warmer SST. Using reanalysis datasets and TC records in the northwestern Pacific and the North Atlantic basins, it is shown that there exists a consistently negative correlation between the annually averaged TC intensity and the basinwide average of the tropospheric static stability. This negative correlation is more robust in the northwestern Pacific basin when using the TC lifetime maximum intensity but is somewhat less significant in the North Atlantic basin. Further separation of the troposphere into a lower (1000-500 hPa) and an upper layer $(500-200 \mathrm{hPa})$ reveals that it is the upper-tropospheric static stability that plays a more dominant role in governing the TC intensity variability. The negating effects of a stable troposphere on TC intensity as found in this study suggest a partial offset of the projected increase in the TC potential intensity due to the future warmer SST. Thus, the tropospheric static stability is one of the key large-scale factors that need to be properly taken into account in studies of long-term TC intensity change.
\end{abstract}

\section{Introduction}

The relationship between tropical cyclone (TC) activity and ambient environmental conditions is one of the focuses in the current TC-climate research. Numerous theoretical and modeling studies along with statistical analyses of past and future climate scenarios have captured several dominant large-scale factors that play a key role in the variability of TC activity including sea surface temperature (SST), vertical wind shear, midlevel moisture, and tropical tropopause-layer temperature (see, e.g., Gray 1968; Goldenberg et al. 2001; Wang et al. 2010; Murakami et al. 2011; Emanuel et al. 2013; Wing et al. 2015; Camargo 2013; Kossin et al. 2016).

Among these large-scale factors, the role of SST has been most extensively studied, particularly from the climate change standpoint. Various studies have used SST as the main proxy to understand and to project changes in TC intensity (Emanuel 2005; Oouchi et al. 2006; Knutson et al. 2010, 2013; Villarini and Vecchi 2013; Murakami et al. 2014). While SST is of great importance in the North Atlantic (NATL) basin, it is

\footnotetext{
Corresponding author: Chanh Kieu, ckieu@indiana.edu.
}

intriguing to observe that the role of SST is somewhat less apparent in other basins such as the northwestern Pacific (WPAC; see, e.g., Emanuel et al. 2013; Lin and Chan 2015; Ferrara et al. 2017). This fact indicates that there must be other large-scale factors beyond SST that control the TC intensity variability in different regions.

In fact, a growing number of modeling and climatological studies have shown some teleconnection between TC activity and different dominant modes of the atmospheric-oceanic oscillations such as El NiñoSouthern Oscillation (ENSO; Wang and Chan 2002; Smith et al. 2007), North Atlantic Oscillation (NAO; Elsner 2003; Elsner and Jagger 2006), or the MaddenJulian oscillation (MJO; Maloney and Hartmann 2000; Kossin et al. 2010; Klotzbach 2010). These large-scale modes could help explain some intricate behaviors of TC climatology in different basins such as the negative correlation between the TC activity in the NATL and the WPAC basins or the interannual variability of the TC frequency (Lander and Guard 1998; Collins and Mason 2000; Wang and Chan 2002; Zhao et al. 2009). These statistical relationships are useful for practical seasonal outlooks or short-term projections, yet they do not fully explain the physical mechanisms behind the TC variability between seasons or basins. 
Using reanalysis data, Emanuel et al. (2013) recently found that the tropical tropopause temperature plays an important role in the long-term trend of the TC maximum potential intensity (MPI) in the NATL basin. This finding was further supported by subsequent modeling and observational studies (e.g., Ramsay 2013; Wang et al. 2014; Wing et al. 2015; Kossin 2015; Kieu et al. 2016; Ferrara et al. 2017; Moon and Kieu 2016). Within the MPI framework, such an impact of the tropical tropopause-layer temperature on MPI is expected because of the dependence of MPI on the energy conversion efficiency; that is, a colder tropical tropopause-layer temperature would allow for more surface enthalpy supply to be converted to TC kinetic energy.

Within the framework of TC-scale dynamics, Kieu and Wang (2017a,b, hereinafter KW17a,b) recently presented a low-order model that reveals a critical role of the tropospheric static stability to MPI beyond the direct convective available potential energy (CAPE) dependence. By relaxing the strict slantwise moist neutrality assumption in Emanuel (1986), a modified MPI expression that displays how TC maximum intensity depends explicitly on the tropospheric static stability was obtained. That is, MPI would be smaller for a more stable troposphere, even under the same SST and outflow condition. This dependence of MPI on the static stability is consistent with previous modeling studies (Shen et al. 2000; Hill and Lackmann 2011; Tuleya et al. 2016) and was recently confirmed in a range of idealized simulations by Kieu and Zhang (2018).

Among several consequences, the most apparent implication of KW17a's MPI expression is that the tropospheric static stability (TSS) can be used as a climate predictor to examine TC intensity variability. From a practical perspective, this MPI-TSS relationship is noteworthy because it introduces a new predictor that could help determine the long-term variability of TC intensity. Many previous studies (e.g., Hill and Lackmann 2011; Sohn et al. 2016; Plesca et al. 2018) showed that the upper-tropospheric warming rate is about twice that in the lower troposphere in the future climate, which will accordingly lead to a more stable environment. Such an increase in TSS would suggest limited storm development in TC main development regions (Sharmila and Walsh 2018). In fact, Hill and Lackmann argued that future TC potential intensity could increase by as much as $19 \%$ due to warmer SST, but through the increase of TSS may reduce this potential intensity increase by $10 \%$. It is therefore prudent to determine the role that the tropospheric stratification will have on TC intensity.

Due to various assumptions in the TC-scale dynamics in $\mathrm{KW} 17 \mathrm{a}, \mathrm{b}$ as well as idealized settings in Kieu and
Zhang (2018), it is, however, unclear if KW17a,b's MPITSS relationship can be realized in the climatological data. In this study, statistical analyses based on reanalysis datasets are used to verify and elucidate the role of TSS in the TC long-term intensity variability. Our main objective is to examine the actual connection between TSS and TC intensity beyond the theoretical and idealized modeling framework, using available reanalysis data and previous TC records.

The rest of this paper is organized as follows. Section 2 introduces the methodology and dataset used in this study. Section 3 presents climatological analyses of the TC intensity and large-scale tropospheric stability. A summary and concluding remarks are given in section 4 .

\section{Method and data}

\section{a. Methodology}

In this study, the role of TSS in the climatological variability of TC intensity is examined, following the results from KW17a,b and Kieu and Zhang (2018). Specifically, we wish to validate the relationship between TSS and the TC potential intensity derived in KW17a,b given by

$$
V_{\mathrm{mPI}}^{2}=V_{\mathrm{PI}}^{2}-\alpha S,
$$

where $V_{\mathrm{PI}}^{2}$ is the MPI value obtained from the original Emanuel's MPI expression (Emanuel 1986), $S$ is the effective tropospheric static stability, $\alpha$ is a proportional constant, and the subscript mPI denotes MPI after taking into account the direct effects of TSS. Note that this dependence of MPI on the static stability as given by Eq. (1) differs from the eyewall CAPE encoded within $V_{\mathrm{PI}}^{2}$ as derived in Bister and Emanuel (2002). Indeed, the central point underlying the derivation of Eq. (1) is the removal of the assumption of a strict moist neutral slantwise convection in the original MPI theory. In a strict moist neutrality condition, convective heating is completely balanced by adiabatic cooling and so $S$ is equal to zero (Kieu 2015). However, real TC development does not exactly maintain the moist neutrality due to the continuous change of the static stability with time as the midlevel becomes warmer (see, e.g., Ooyama 1969; Vigh and Schubert 2009). Therefore, it is not reasonable to assume $S=0$, which subsequently introduces an extra effect to MPI as given by the second term on the right-hand side of Eq. (1) [see KW17a,b and Kieu and Zhang (2018) for more details].

While the proportional constant $\alpha$ can be explicitly derived from the TC-scale dynamics framework as shown in KW17a,b, it will be, however, treated as a regressional coefficient in this study from the climatological 
perspective due to various simplifications in the TC-scale model that may not be applicable in real TCs. Our aim is to verify if the TC maximum intensity depends on TSS as dictated by Eq. (1), that is, the TC maximum intensity would be weaker for a more stable troposphere. The validity of this relationship will support the use of TSS as a climate predictor for the study of the TC intensity variability beyond the classical MPI framework.

To examine Eq. (1), it is necessary to first obtain the effective static stability information from climate data. While the static stability can be easily calculated, it should be noted that the effective static stability is harder to quantify as it requires calculation of a saturated moist profile at each stage of TC development. Because our focus here is more on the climatological aspect of Eq. (1) from the large-scale perspective, a simple procedure of obtaining the effective static stability is thus desired for practical purposes. Thus, we will adopt a simple strategy by hereinafter defining $S \equiv \Gamma_{d}-\Gamma$, where $\Gamma_{d}=g / C_{P}$ is the dry adiabatic lapse rate and $\Gamma=-(d T / d z)$ is the environmental lapse rate. The impact of the effective static stability is then assumed to be absorbed in the regressional coefficient $\alpha$. Note that this definition of $S$ differs from the definition of the actual static stability by a factor $g / \bar{T}$, where $\bar{T}$ is the mean temperature of the troposphere. However, this factor can be also absorbed in the proportional constant $\alpha$ such that the calculation of $S$ can be readily obtained from climate data. A positive value for the coefficient $\alpha$ will imply that the TC maximum intensity decreases as TSS increases, and vice versa.

With the above definition of $S$, two levels 1000 and $200 \mathrm{hPa}$ are chosen in this study to compute $\Gamma$ at each grid point of the reanalysis data as follows:

$$
\Gamma=\frac{T_{1000}-T_{200}}{\Delta Z}
$$

where the thickness $\Delta Z$ of the $1000-200 \mathrm{hPa}$ layer is given by

$$
\Delta Z=-\frac{R}{g} \int_{1000}^{200} \frac{T_{v}}{p} d p .
$$

The mean environmental lapse rate is then averaged for each ocean basin in two different ways: 1) a basinwide average to capture the entire basin environment each year, and 2) a storm-centered average to capture the ambient environment that is centered on individual TC. For the basinwide environment, an area average of the lapse rate is carried out to represent the large-scale characteristics of the troposphere during the main TC season for the whole basin. The domain to be taken average in this basinwide average is $\left[5^{\circ}-35^{\circ} \mathrm{N}\right] \times\left[110^{\circ}-170^{\circ} \mathrm{E}\right]$ during
May-October for the WPAC basin and $\left[10^{\circ}-35^{\circ} \mathrm{N}\right] \times$ $\left[80^{\circ}-30^{\circ} \mathrm{W}\right]$ during May-October for the NATL basin, which cover most of TC development.

For the basinwide average of TSS, we note that the domain for the calculation of the area average of TSS and the range of the months for the annually averaged TC intensity are not independent. In fact, the domain size and the months must be based on the ocean surface coverage and the TC main activity region. With our specific focus on the static stability over the ocean area where TCs develop, it is important to minimize the direct land surface in all TSS average, whose static stability is not directly relevant to TC development. Given the domain size for the area average of TSS, the months are thus chosen such that they could contain most TCs in that domain.

For the storm-centered environment, the location of the lifetime maximum intensity (hereinafter $V_{\max }$ ) of each TC is searched and a spatial average of environmental lapse rate is then calculated around the TC center location recorded at the time of $V_{\max }$. Specifically, a box of $2000 \mathrm{~km} \times 2000 \mathrm{~km}$ around the storm center was used to compute the averaged lapse rate at each $V_{\max }$ location. This domain size is based on the typical radial scale of TCs of order $\sim 10^{3} \mathrm{~km}$ such that the area average can closely capture the ambient environment surrounding most TCs.

Note that because each storm typically has one $V_{\max }$ value, the squared box centered on the location of $V_{\max }$ for each storm is generally well defined, thus allowing us to compute the storm-centered average as expected. The only exception is when a storm has the same $V_{\max }$ value at different locations along its track. In this case, we simply take the average of all lapse rates for different locations such that one storm in a given year has only one value of $V_{\max }$ and one value of a mean lapse rate corresponding to that $V_{\max }$. Because the storm-centered average is taken within an area centered on the TC center at its lifetime maximum intensity, this average can better represent the actual ambient environment that TCs develop in than the basinwide average.

As a further step to see the relative contribution of the stratification in the upper troposphere versus lower troposphere to the overall variability of TC intensity, separate calculations of static stability for two tropospheric layers, 1000-500 hPa (lower layer) and 500-200 $\mathrm{hPa}$ (upper layer), are conducted alongside with the entire layer TSS averaged between 1000 and $200 \mathrm{hPa}$. By comparing the relationships between TC intensity and TSS in different layers, one can investigate which layer of the troposphere is the most influential on TC intensity. This is expected because the TC baroclinicity 
with a more dominant cyclonic flow in the lower troposphere could result in different impacts of the tropospheric stability on TCs. Note that the lower half of the troposphere contains the boundary layer, where the boundary convergence is strongest. In contrast, the upper-level stratification determines the ability of TC outflow to develop, which can enhance both vertical and radial stratification of the outflow. The relative contribution of the lower- and upper-tropospheric layers thus motivates us to examine their separate influence on TC intensity variability. By design, all mean static stability for the upper, lower, and entire tropospheric layers are calculated for both the basinwide and the storm-centered averages.

Given the averaged static stability $S$ for the basinwide and storm-centered environments, our next step is to define a TC maximum intensity metric. Although the theoretical limit $V_{\mathrm{PI}}^{2}$ can be computed by using an iterative method from a given sounding input as described in Emanuel's MPI code, ${ }^{1}$ it should be noted that the calculation of $V_{\mathrm{mPI}}^{2}$ in Eq. (1) is not possible a priori, due to the unknown coefficient $\alpha$. In fact, it is our goal to verify if the functional form given by Eq. (1) is correct, from which one can estimate the proportional coefficient $\alpha$ from the climate data. Thus, it is important to have a proper TC maximum intensity metric that could represent $V_{\mathrm{mPI}}^{2}$ variability.

Due to the lack of prior knowledge of the theoretical MPI that a TC can attain in real atmosphere, two metrics for the TC maximum intensity will be attempted to represent $V_{\mathrm{mPI}}^{2}$ in this study. These metrics are 1) the annually averaged TC intensity and 2) the lifetime maximum intensity. For the annually averaged intensity metric (denoted as $\bar{V}^{2}$ ), the average of all available $10-\mathrm{m}$ sustained winds of all storms that are above the tropical depression threshold (i.e., $>17 \mathrm{~m} \mathrm{~s}^{-1}$ ) is computed for each basin in each year. To some extent, this annually averaged intensity represents the bulk measure of both intensity and lifetime of TCs in each year similar to the accumulated cyclone energy (e.g., Bell et al. 2000; Klotzbach 2014). In contrast, the second intensity metric (i.e., $V_{\max }^{2}$ ) is the maximum sustained wind that a storm has reached during its life cycle. For both intensity metrics, the $10-\mathrm{m}$ sustained wind is squared to be consistent with the MPI equation.

We emphasize that neither the lifetime maximum intensity nor the annually averaged intensity can fully represent the potential intensity $V_{\mathrm{mPI}}^{2}$, because it is never known if a storm may have reached its MPI

\footnotetext{
${ }^{1}$ The MPI code is based on Bister and Emanuel (2002), which is available at ftp://texmex.mit.edu/pub/emanuel/TCMAX/.
}

value or not during its development in real atmospheric conditions. Nevertheless, the studies of Emanuel (2000) and Gilford et al. (2017, 2019) imply at least that $V_{\max }$ is closely related to MPI in terms of the seasonal variability. As such, it is expected that the interannual variability of $V_{\max }$ and its correlation with TSS should reflect some degree of variability of the theoretical limit $V_{\mathrm{mPI}}^{2}$ that we wish to verify in this study.

Unlike the basin-averaged intensity that has only one data point for each year, $V_{\max }$ is always found for every storm, and so the number of data points for this $V_{\max }$ metric in each year is the same as the number of TCs in that year. Because of this, the number of the $V_{\max }$ data points is much larger than that of the annually averaged intensity $\bar{V}$, allowing for more robust statistics. As a way to look into different manifestations of the statistical significance and correlation for the strong versus overall TC statistics, additional statistics of strong TCs (i.e., TCs with category 3 and above) is also carried out. This strong TC analysis can be compared with the statistics of all TC categories for more insight about the relationship between TSS and $V_{\max }$.

\section{b. Data}

In this study, the National Centers for Environmental Prediction-National Center for Atmospheric Research (NCEP-NCAR) reanalysis (Kalnay et al. 1996) data are used for our analysis of the large-scale stratification of the troposphere. Our use of the NCEP-NCAR reanalysis data is not only based on the fact that these data have the longest record of the entire atmospheric structure, but also because of the consistency between the atmospheric stratification and the SST distribution. One could in principle employ different SST datasets such as the Hadley Centre Sea Ice and Sea Surface Temperature data (HadISST; Rayner et al. 2003). However, the inconsistencies between different SST data and the atmospheric structure in the NCEP reanalysis would make it difficult to obtain or interpret any statistical relationship. Due to this consistency requirement between the atmospheric structure and SST, the NCEP-NCAR reanalysis and SST are chosen for all of our statistical analyses herein. By default, the NCEP reanalysis contains threedimensional distributions of geopotential height and temperature at standard pressure levels, as well as SST distribution recorded four times daily at a spatial resolution of $1^{\circ} \times 1^{\circ}$, These variables allow one to effectively compute the environmental lapse rate as well as its basinwide and storm-centered averages for our analyses of the variability of the environmental conditions. 
For the TC data, the best track dataset provided by Joint Typhoon Warning Center (JTWC) in the WPAC basin and the most updated NHC "best track" hurricane databases (HURDAT; Landsea et al. 2014) in the NATL basin are used. While the NHC/JTWC datasets contain TC records from 1948 to 2017, these full records cannot be used for the statistics of TC intensity. For the NATL basin, routine aircraft reconnaissance has been present in the basin since the mid-1940s, but these aircraft observations suffer a range of issues such as the lack of routinely penetrating the eye of extreme TCs or inaccurate estimation of flight-level and surface winds until the late 1970s (Uhlhorn and Black 2003; Delgado et al. 2018; Sheets 1990; Chang and Guo 2007; Rappaport et al. 2009). In addition, TCs of major hurricane category have been shown to be biased during the 1940 s to 1960 s because of the practice to estimate surface winds visually, resulting in the substantial low bias in peak intensities and TC lifetime, as well as an underestimation of major TCs before the satellite era in 1974 (Landsea 1993; Delgado et al. 2018; Landsea et al. 2010; Villarini et al. 2011). Because of these issues, all analyses of TC intensity for the NATL basin in this study are carried out only for a shorter period from 1975 to 2017.

For the WPAC basin, the TC database maintained by JTWC has many similar issues. As described in Chu et al. (2002) and Landsea et al. (2006), this basin has constantly undergone changes in observing systems and retrieval methodologies. While aircraft reconnaissance was available by 1948 , these early data only covered the southwestern half of the basin with few surface wind observations and inaccurate flight-level winds (Hagen and Landsea 2012; Delgado et al. 2018). The first geostationary satellite and the Dvorak technique was only available after 1975 (Dvorak 1975, 1984), and aircraft reconnaissance in this basin ended in the middle of 1980s. Because of these mixed issues with data quality, the use of JTWC data for peak intensity and location is limited from 1988 to 2017 in this study for the data homogeneity.

It should be mentioned that unlike the HURDAT dataset in the NATL basin, there are currently several other TC datasets in the WPAC basin that are quite different in terms of the maximum surface wind and the storm latitude/longitude (see, e.g., Song et al. 2010; Kamahori et al. 2006). On average, the JTWC dataset seems to overestimate the storm intensity compared to the two other datasets from the Japan Meteorological Agency and the Shanghai Typhoon Institute. Given such uncertainties in the intensity estimation in the WPAC basin, the JTWC dataset is chosen in this study to be consistent with the dataset from the National
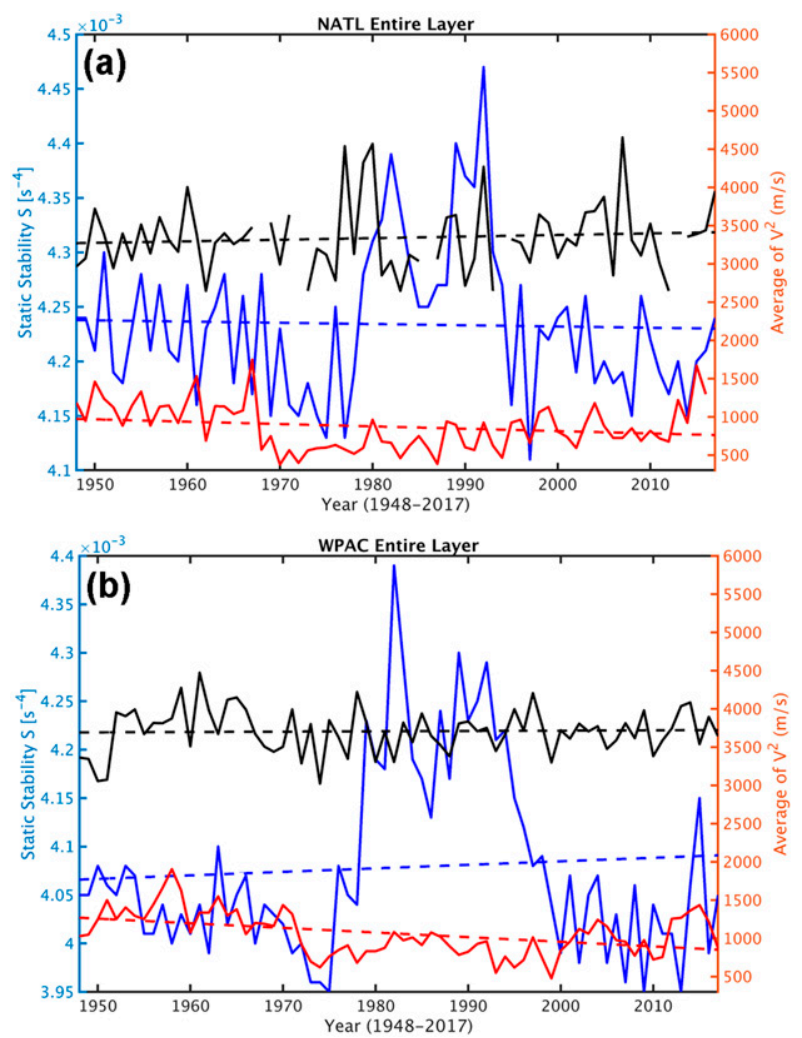

FIG. 1. (a) Time series of the tropospheric static stability $S \equiv \Gamma_{d}-\Gamma$ (blue), annually averaged $\bar{V}^{2}$ (red), and averaged $\bar{V}^{2}$ for category 3-5 storms only (black) for the NATL basin from 1948 to 2017, along with the corresponding trend lines (dashed). (b) As in (a), but for the WPAC basin.

Hurricane Center. Both JTWC and the National Hurricane Center use similar Dvorak techniques in determining TC intensity, and so they are to some extent more homogeneous for intercomparison between the two basins.

\section{Results}

\section{a. Basinwide averaged static stability impacts}

To first have a broad picture of the trends of TSS and TC intensity during the entire 80 -yr period from 1948 to 2017 in both basins, Fig. 1 shows the time series of the basinwide averaged TSS along with the corresponding annual average of intensity $\bar{V}^{2}$. As seen in Fig. 1, there is no significant trend of TSS in either the NATL or the WPAC basins during 1948-2017. The most noticeable feature is a surge of TSS between 1980 and 1990, which is evident in both basins. Further examination of the relative contribution of the upper and lower troposphere shows that this surge is mostly driven by the change in the upper-tropospheric stratification from 500 
to $100 \mathrm{hPa}$ layer (not shown). Such an abrupt increase in the upper TSS is consistent with the surge of the tropopause temperature and the lower-stratospheric stratification during the same period as reported in Ferrara et al. (2017).

The fact that this drastic global change in the upper troposphere/lower stratosphere starts at the same time that the satellite data retrieval of the tropospheric temperature began in early 1970 is noteworthy. Specifically, the surge in TSS raises a question of whether or not this feature is an artifact of the NCEP-NCAR reanalysis data due to the inclusion of satellite data, or it is an actual characteristic of the upper troposphere during this period. Unfortunately, there is no observational dataset with a complete atmospheric structure that extends all the way back to 1948 as the NCEP-NCAR reanalysis in order to verify this feature. The lack of a good upper-level observational network prior to the satellite era makes it hard to verify this abrupt change in the upper troposphere during 1980-90. Note that if we remove this surge of TSS from 1980 to 1990 by confining our analysis only to the postsatellite area (i.e., 19982017), the trend of TSS in the NATL basin is still almost unchanged, while there is a more significant increase in TSS in the WPAC basin similar to what was reported in Sharmila and Walsh (2018).

For the annually averaged TC intensity $\bar{V}^{2}$, there appears to be a slight downward trend in both basins, especially in the WPAC whose decreasing trend is more apparent during the whole 1948-2017 period (albeit not statistically significant). It should be mentioned, however, that if the postsatellite era is used similarly to previous studies (e.g., Lin and Chan 2015), the $\bar{V}^{2}$ uptrends are seen in both basins with a larger trend in the NATL basin. As discussed in Landsea (2007), such different trends in the TC intensity between the presatellite and postsatellite periods are likely due to the monitoring system as well as the quality of the TC intensity estimation associated with different intensity analysis techniques, which are difficult to conclusively separate. Similar analyses for intense TCs of category 3-5 also capture a minor decreasing trend in the NATL basin and no trend in the WPAC basin during 1948-2017 (see the black curves in Fig. 1). Unlike the overall $\bar{V}^{2}$ for all TC categories, there is no significant difference between the entire period (1948-2017) and postsatellite period (1980-2017) for intense TCs in both basins.

Because the trend analyses can only display the overall tendency with time instead of correlations between TC intensity and TSS, Fig. 2a shows a scatterplot of the basinwide averaged static stability $S$ and $\bar{V}^{2}$ during the 1975-2017 period for the NATL basin and 1988-2017 for the WPAC basin. It can be seen in Fig. 2
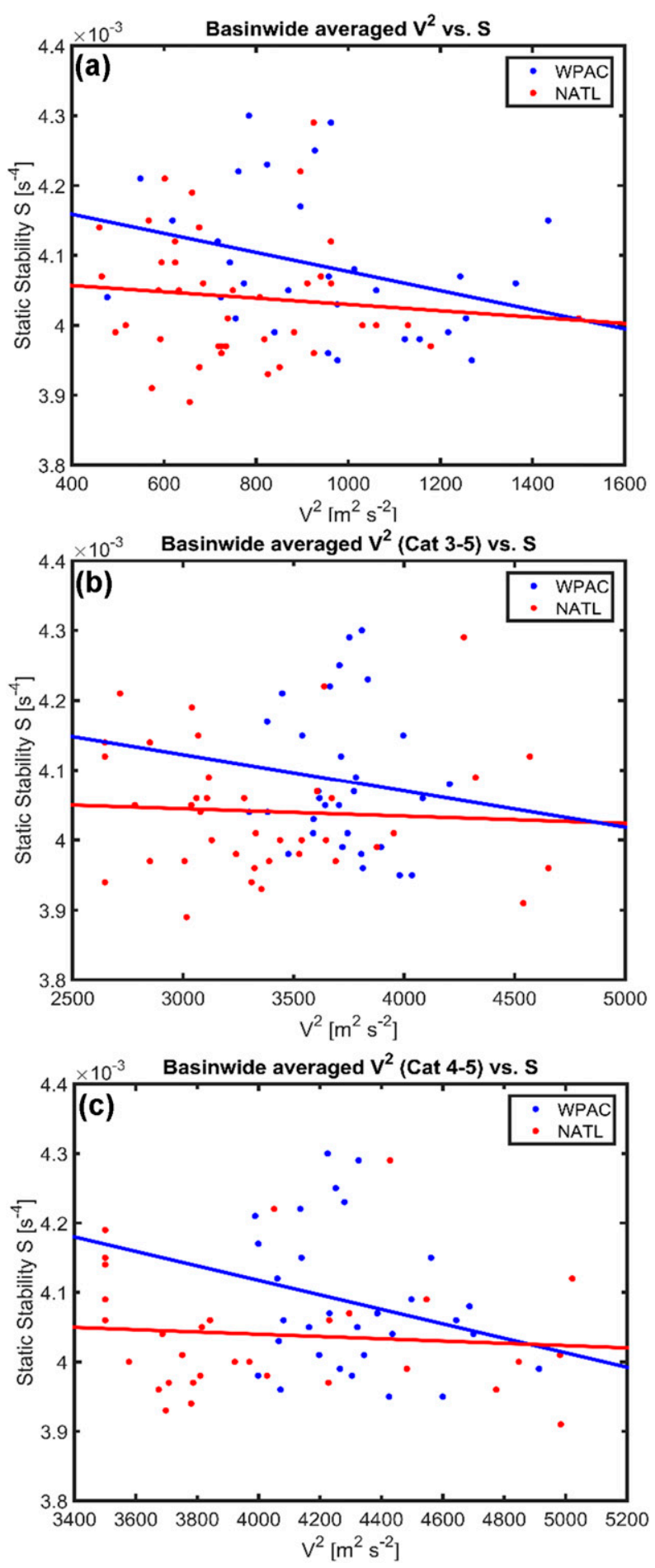

FIG. 2. (a) Scatterplots of the basinwide averaged static stability $S$ for the entire tropospheric layer vs the annually averaged TC intensity $\bar{V}^{2}$ for the NATL basin during 1975-2017 (red) and WPAC basin during 1988-2017 (blue). (b) As in (a), but for intense TCs of category 3-5, (c) as in (a), but for category 4-5. Solid lines denote the least-squared best fits, and the dots denote the data point each year. 
TABLE 1. Correlation between the basinwide average of the tropospheric static stability $S$ and the annually averaged TC intensity $\bar{V}^{2}$, along with the corresponding $p$ values.

\begin{tabular}{lccc}
\hline \hline NATL (1975-2017) & Correlation & $p$ value & $\begin{array}{c}\text { No. of data } \\
\text { points }\end{array}$ \\
\hline All storms & -0.1121 & 0.48 & 43 \\
Category 3-5 & -0.0613 & 0.71 & 34 \\
Category 4-5 & -0.0903 & 0.63 & 27 \\
WPAC (1988-2017) & & & \\
All storms & -0.3202 & 0.08 & 30 \\
Category 3-5 & -0.1089 & 0.57 & 30 \\
Category 4-5 & -0.2422 & 0.19 & 30 \\
\hline
\end{tabular}

that there is a negative correlation between $\bar{V}^{2}$ and $S$ in both basins, with the correlation of $\sim-0.11$ in the NATL and considerably higher $(\sim-0.32)$ in the WPAC basin. This negative correlation indicates that the more stable atmosphere (i.e., a larger TSS) would correspond to an overall weaker TC intensity, in accordance with the positive coefficient $\alpha$ in Eq. (1) (i.e., a negative slope with respect to TSS). Between these two basins, note that the negative correlation in the WPAC has a larger statistical significance (at $90 \%$ confidence interval) as shown in Table 1. Even though these correlations are generally small, the fact that they are consistent in both basins suggests that TSS does play a role in the interannual variability of TC intensity.

To further examine the relative difference between the all TC categories and intense TCs, the $V^{2}-S$ scatterplot for intense TCs of category 3-5 TCs is provided in Fig. $2 b$. In general, the negative correlations are still apparent in both basins, but the statistical significance is no longer robust in both basins. Our attempt to refine the definition of intense TCs with category 4-5, which is to some extent a better measurement of TC potential intensity than the annually averaged intensity of all TC categories, does seem to increase the negative correlation in both basins (Fig. 2c). However, the statistical significance does not show much differences, especially in the NATL basin, which is likely due to the lack of strong storms in this basin (see Table 1). As shown in Fig. 1, there were a number of years during 1948-2017 that the NATL basin did not even have any record of category 3-5 TCs (see the gaps in the black line in Fig. 1a). Regardless of how TCs are classified, it is noted that the WPAC basin always possesses a consistently stronger negative correlation between TSS and $\bar{V}^{2}$ than the NATL basin. This negative correlation reiterates the dependence of TC intensity on the effective static stability as given by Eq. (1), whereby the more stable tropospheric tends to result in an overall weaker TC intensity.

It should be noted that the negative correlation between TSS and the annually averaged intensity is not sufficient to conclude that a higher environmental stratification must result in a weaker TC intensity. This is because the variation of TSS is also connected to changes in SST or tropopause temperature, which could also modify $V_{\mathrm{mPI}}^{2}$ in addition to the dependence on static stability. For example, a warmer tropopause temperature implies not only a more stable troposphere (i.e., a larger $S$ ) but also a warmer outflow temperature. As a result, $V_{\mathrm{mPI}}^{2}$ would be weaker due to less energy efficiency (i.e., a smaller $V_{\mathrm{PI}}^{2}$ ) as well as the more stable troposphere (i.e., larger $S$ ) according to Eq. (1). Similarly, any increase or decrease in SST can affect both $V_{\mathrm{PI}}^{2}$ and $S$, which leads to a change in $V_{\mathrm{mPI}}^{2}$. Thus, it would be difficult to attribute a weaker $V_{\mathrm{mPI}}^{2}$ exclusively to a weakened efficiency, less enthalpy exchange, or a more stable troposphere due to their simultaneous changes. The relative importance of TSS, tropopause temperature, and SST in the overall variability of TC intensity can be therefore addressed only if one can fix all factors except one. Using different idealized designs in which TSS was varied while SST and outflow temperature were kept fixed, recent simulations by Kieu and Zhang (2018) demonstrated that the contribution from TSS is significant [see Fig. 4 in Kieu and Zhang (2018) and discussions therein]. In this regard, the negative correlation shown in Fig. 2 may reflect the actual effects of TSS on TC intensity as dictated by Eq. (1) rather than the mere changes in the tropopause temperature or SST.

\section{b. Storm-centered stratification}

Because the analyses in Fig. 2 focus only on the basinwide average of TSS and annually averaged intensity, these analyses may not fully characterize the immediate ambient environment that a TC reaches its peak intensity during its development. To further examine the relationship between TC intensity and the environmental conditions that are directly relevant to TC development, Fig. 3 shows a similar analysis as Fig. 2, but with the static stability $S$ now computed for an area of $2000 \mathrm{~km} \times 2000 \mathrm{~km}$ around the center of each TC at its lifetime maximum intensity. We note here again that this TC intensity metric is no longer the averaged intensity of all storms in a given year. Instead, the TC intensity metric is defined as the largest value of the $10-\mathrm{m}$ sustained wind during the lifetime of each TC. Because of this, the data sample is much larger than that in the basinwide average analyses, allowing for more robust statistics.

Figure 3a shows the scatterplot of $V_{\max }^{2}$ and TSS during 1975-2017 and 1988-2017 for NATL and WPAC, respectively. One notices that a larger negative correlation between $V_{\max }^{2}$ and TSS is now captured in both basins, thus reiterating the fact that a more stable tropospheric environment would correspond to weaker 

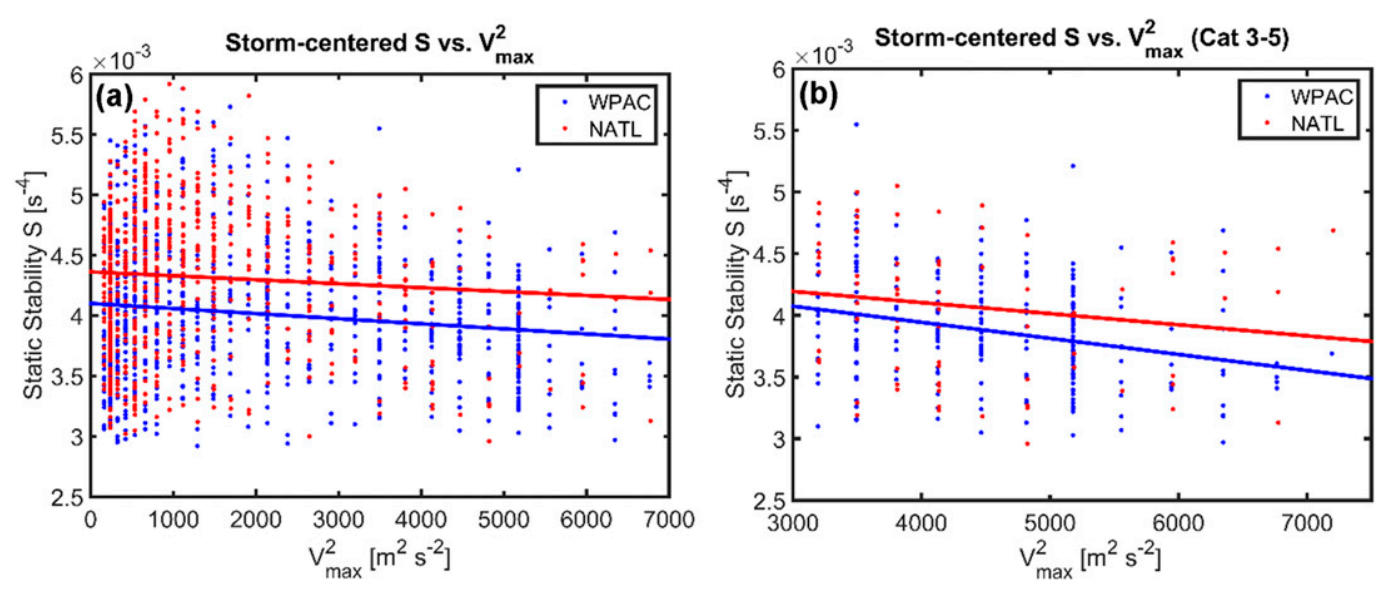

FIG. 3. As in Fig. 2, but for storm-centered tropospheric static stability and the lifetime maximum intensity $V_{\max }^{2}$ of (a) all TC categories, and (b) intense TCs of category 3-5 only.

storms. It is, however, intriguing to see that the correlation values are somewhat smaller than those obtained in the basinwide average analyses, due likely to the larger scattering of the data points. The most noticeable change is, however, the statistical significance levels in both basins that are now at a $90 \%$ confidence interval, especially in the WPAC basin (Table 2). Similar to the basinwide average, it is observed that the WPAC has a larger negative correlation $(\sim-0.14)$ as compared to the NATL basin $(\sim-0.07)$, confirming the more essential role of TSS in the WPAC basin.

Additional examination of intense TCs that includes only those with categories 3-5 confirms the negative correlations between $V_{\max }^{2}$ and TSS, with a $p$ value $\sim 0.04$ for the NATL basin and $<0.01$ for the WPAC basin (Fig. 3b and Table 2). The only exception is for intense TCs defined as those with category 4-5 in the NATL basin, whose $p$ value for the correlation between $S$ and $V_{\max }^{2}$ is relatively large $(\sim 0.72$; see Table 2$)$. Such a high $p$ value in the NATL basin for category 4-5 TCs regardless of TC intensity metrics is possibly related to not only the lack of strong storms but also larger variability

TABLE 2. As in Table 1, but for the correlation analyses for the storm-centered average of TSS over the entire tropospheric layer and the TC lifetime maximum intensity $V_{\max }^{2}$.

\begin{tabular}{lccc}
\hline \hline NATL (1975-2017) & Correlation & $p$ value & $\begin{array}{c}\text { No. of data } \\
\text { points }\end{array}$ \\
\hline All storms & -0.0722 & 0.06 & 666 \\
Category 3-5 & -0.1884 & 0.04 & 112 \\
Category 4-5 & -0.0447 & 0.72 & 67 \\
WPAC (1988-2017) & & & \\
All storms & -0.1355 & $<0.01$ & 854 \\
Category 3-5 & -0.3019 & $<0.01$ & 263 \\
Category 4-5 & -0.2896 & $<0.01$ & 212 \\
\hline
\end{tabular}

associated with the dominant effects of SST (see, e.g., Emanuel et al. 2013; Gilford et al. 2019). Therefore, the SST warming in the NATL may offset the detrimental impacts of a more stable troposphere, and explain why the $V_{\max }^{2}$-TSS correlation in the NATL basin is not significant in both the basinwide and storm-centered analyses.

\section{c. Upper-versus lower-tropospheric stratification}

Another motivating question related to the effects of TSS on TC intensity is what part of the troposphere contributes the most to the relationship between TSS and TC intensity. This question is of interest because it helps identify the tropospheric layer that could have more of an influence on the TC intensity variability. While Eq. (1) indicates that it is the stratification of the entire tropospheric layer that is of more relevance from the theoretical standpoint, a question of whether the lower half or upper half of the troposphere is more important to the variability of TC maximum intensity can bring new insight in TC development, similar to the different effects of the deep-layer shear versus upper- or lower-layer shear (e.g., Ryglicki et al. 2018).

In this regard, Figs. 4 and 5 show the correlation analyses for the basinwide averaged and storm-centered TSS in the upper and lower troposphere separately. It is of interest to notice from these analyses a quite different effect of TSS between the two layers. In the NATL basin, the negative correlation between the TC intensity and the TSS in the upper-tropospheric layer is similar to the overall correlation for the entire TSS. However, the $\bar{V}^{2}-S$ correlation turns out to be insignificant for the TSS in the lower troposphere, albeit none of these basinwide correlations are statistically significant. Similar 

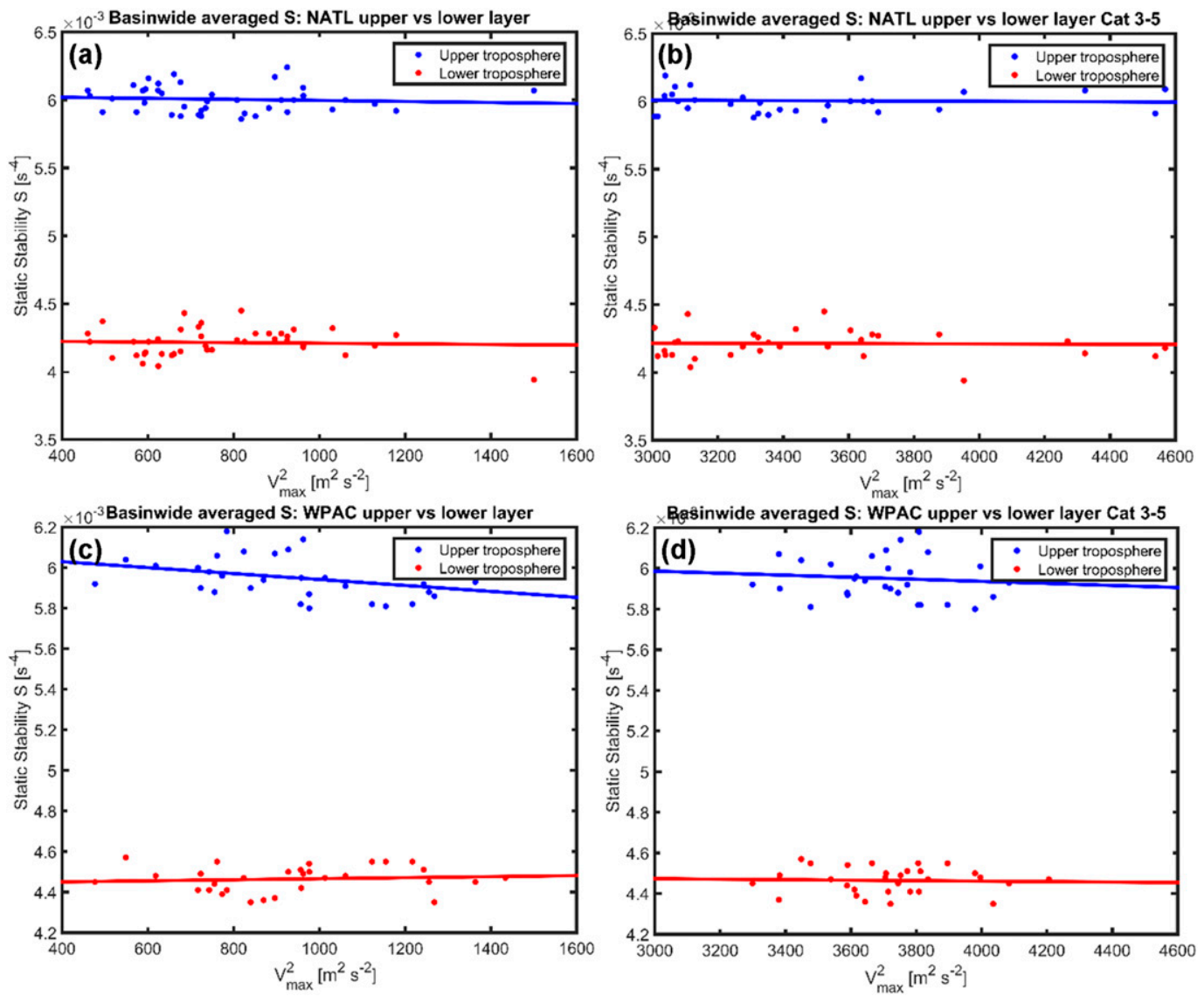

FIG. 4. As in Fig. 2, but for the basinwide averaged static stability $S$ in the upper-tropospheric-layer (blue)/lowertropospheric-layer (red) and the annually averaged TC intensity $\bar{V}^{2}$ for (a) all TC categories in the NATL basin, (b) intense TCs of category 3-5 in the NATL basin, and (c),(d) as in (a),(b), but for the WPAC basin.

analyses for intense TCs (categories 3-5) capture again the opposite correlation between the two layers and TC intensity in the NATL basin (see Fig. 4b and Table 3).

Between the lower- and upper-tropospheric correlations in the NATL, it is noted further that the lower-tropospheric static stability tends to have the least significant impacts on TC intensity with very large $p$ values for both the basinwide and the storm-centered analyses $(>0.5)$. Thus, this lower- versus upper-tropospheric analysis suggests that the static stability in the upper troposphere is more influential with regard to the overall TC intensity variability in the NATL basin. Consistent with the basinwide analyses in Fig. 3, a more significant statistics is only realized for the storm-centered analyses in the lower troposphere, with the $p$ value $<0.05$ and the negative correlation of $\sim-0.1$.

For the WPAC basin, the results somewhat differ from those in the NATL with larger negative correlations between $\bar{V}^{2}$ and TSS in the upper troposphere for both the basinwide and storm-centered averages. Moreover, the correlations in the WPAC basin are more statistically significant than those in the NATL as seen in Table 3, regardless of using all TC categories or just intense TCs. The only exception is the correlation between basinwide averaged TSS in the lower troposphere, which shows a small positive correlation of $\sim 0.1$ with $p$ value $\sim 0.61$ ). Overall, the upper troposphere still displays a larger negative correlation with $\bar{V}^{2}$ as compared to the lower troposphere, which is very similar to that seen in the NATL basin (Table 3). For the stormcentered average, the statistics of $V_{\max }^{2}$ is much more significant than the basinwide average $\bar{V}^{2}$, with $p$ value $<0.01$ for both the upper and lower troposphere in the WPAC basin. The persistent negative correlation between the upper-layer TSS and TC intensity in both basins indicates the dominant effects of the upper troposphere static stability on the TC maximum intensity. This significant result reveals subtle impacts of the static stability, especially given that the upper-troposphere warming rate is larger than that in the lower troposphere in the future warming climate (e.g., Hill and Lackmann 2011). 

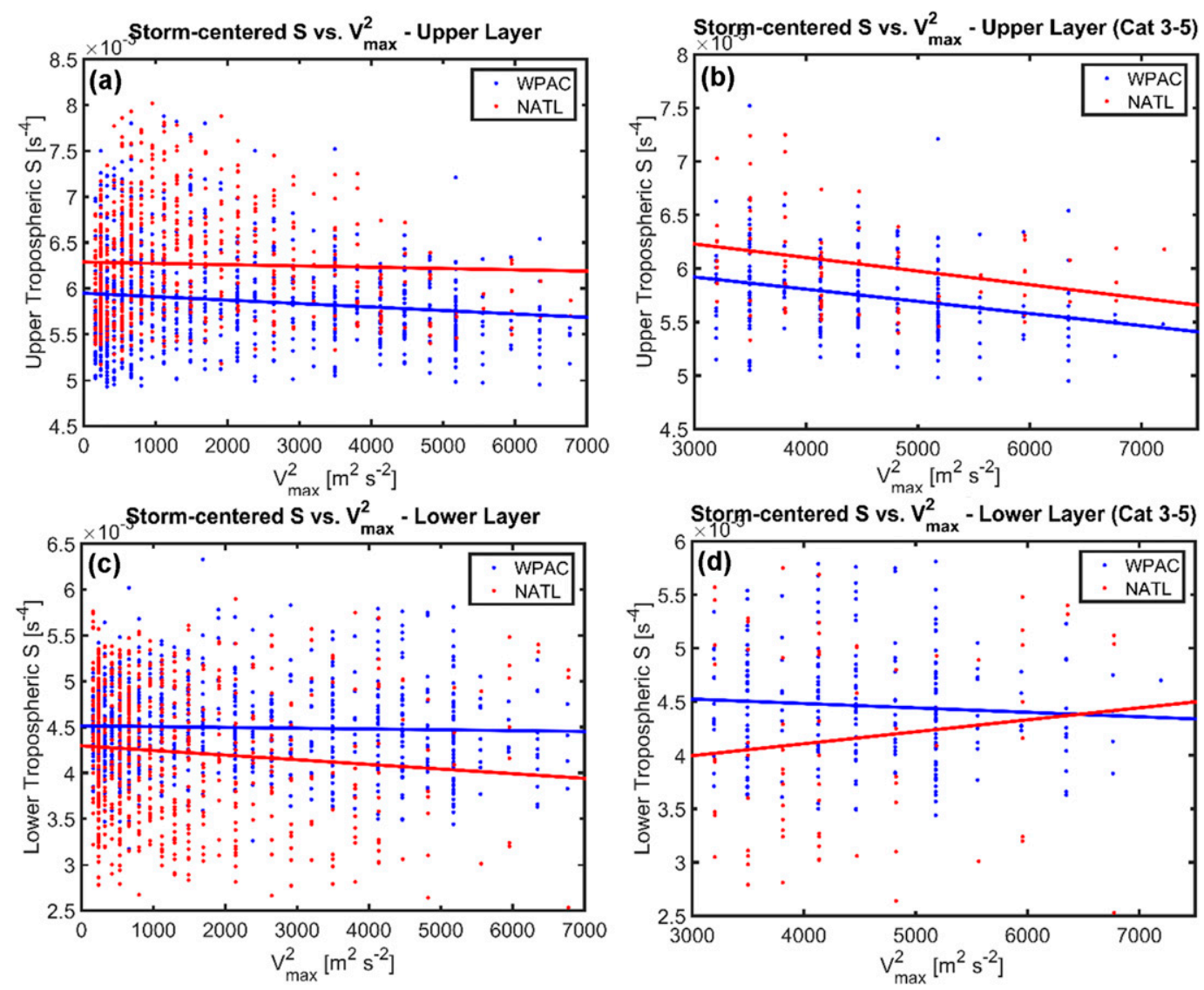

FIG. 5. As in Fig. 3, but for (a) the upper-tropospheric-layer static stability and the lifetime maximum intensity $\left(V_{\max }^{2}\right)$ for all TC categories, and (b) the upper-tropospheric-layer static stability and intense TCs of category 3-5. (c),(d) As in (a),(b), but for the lower-tropospheric-layer static stability.

\section{d. SST confounding effect}

While the analyses in Figs. 2-4 could demonstrate the relationship between the TC maximum intensity and TSS, such a relationship is still elusive due to the

TABLE 3. As in Table 2, but for the correlation between $V_{\max }^{2}$ and storm-centered average of TSS in the upper- $(500-200 \mathrm{hPa})$ and lower-tropospheric layer $(1000-500 \mathrm{hPa})$.

\begin{tabular}{lccc}
\hline \hline \multicolumn{1}{c}{ NATL (1975-2017) } & Correlation & $p$ value & $\begin{array}{c}\text { No. of data } \\
\text { points }\end{array}$ \\
\hline Basinwide lower layer & -0.0479 & 0.76 & 43 \\
Category 3-5 lower layer & -0.0315 & 0.85 & 112 \\
Storm-centered lower layer & -0.0943 & 0.01 & 666 \\
Basinwide upper layer & -0.0866 & 0.59 & 43 \\
Category 3-5 upper layer & -0.0452 & 0.78 & 112 \\
Storm-centered upper layer & -0.0325 & 0.40 & 666 \\
WPAC (1988-2017) & & & \\
Basinwide lower layer & 0.0960 & 0.61 & 30 \\
Category 3-5 lower layer & -0.0826 & 0.17 & 263 \\
Storm-centered lower layer & -0.0330 & 0.32 & 854 \\
Basinwide upper layer & -0.3456 & 0.06 & 30 \\
Category 3-5 upper layer & -0.2982 & $<0.01$ & 263 \\
Storm-centered upper layer & -0.1239 & $<0.01$ & 854 \\
\hline
\end{tabular}

multivariate nature of TC intensity variability. Two particular issues with the statistics of TC intensity derived from the raw data record are 1) the observed TC intensity is a complex multivariate function of many other environmental factors such as SST, outflow temperature, stratification, midlevel moisture, or vertical wind shear for which we do not know an explicit functional form; and 2) the dependence of TC intensity on TSS may not be a simple linear function but potentially nonlinear. These issues are important to address, because it is possible that the TC maximum intensity is inversely proportional to the static stability, yet one may still obtain a positive correlation between the observed TC maximum intensity and TSS if the change in SST has a greater influence than that induced by a change in TSS. Due to the lack of a better functional form between the TC maximum intensity and TSS, we will focus on the first issue in this section, assuming that the linear relationship is sufficient.

Among many other environmental factors, SST is the most critical factor for TC maximum intensity, at least in the NATL basin where correlation between TC 

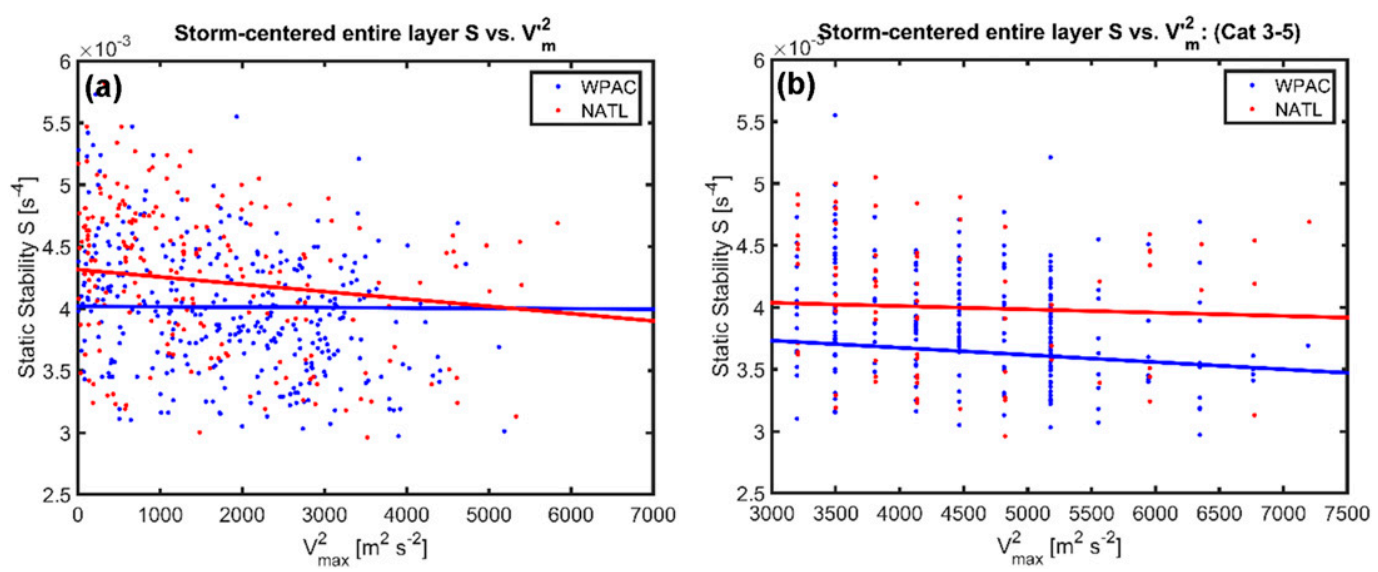

FIG. 6. Scatterplots of the TC lifetime maximum intensity $V_{\max }^{2}$ and the storm-centered average of the entire tropospheric static stability $S$ after reducing the confounding effects of SST in the NATL basin (red) and the WPAC basin (blue) for (a) all TC categories intensity, and (b) for TCs of category 3-5 only.

intensity and SST could reach as large as 0.65 for some metric of intensity such as the accumulated cyclone energy (ACE; Emanuel 2005), or power dissipation index (PDI; Villarini and Vecchi 2013; Murakami et al. 2014; Ferrara et al. 2017). Such an apparent importance of SST is essentially encoded in the first term $V_{\mathrm{PI}}^{2}$ in Eq. (1); a warmer SST results in direct enhancement of surface enthalpy fluxes as well as an increase in the thermal efficiency, and henceforth produces a higher TC intensity (Emanuel et al. 2013; Wing et al. 2015). For TSS, note that a warmer SST also implies a less stable troposphere (assuming the same outflow temperature and tropospheric depth). These confounding impacts of SST on the surface enthalpy, thermodynamic efficiency, and TSS make it hard to isolate the actual role of TSS in the variability of the TC maximum intensity.

As a first-order approximation, the relative role of static stability relative to SST is examined in this section by reducing the direct impacts of SST on TC intensity variability. Specifically, we consider a simplification in which the direct role of SST on the TC maximum intensity is eliminated from $V_{\max }^{2}$ as follows:

$$
V_{m}^{\prime 2} \equiv V_{\mathrm{PI}}^{2}-V_{\max }^{2},
$$

where $V_{\mathrm{PI}}^{2}$ is obtained from Emanuel's MPI code. The statistical analyses between TSS and TC intensity are then conducted for the residual $V_{m}^{\prime 2}$ instead of the observed lifetime maximum intensity $V_{\max }^{2}$. Note that this subtraction of $V_{\mathrm{PI}}^{2}$ from the TC maximum intensity as in Eq. (4) is based on a premise that the most direct role of SST is contained in $V_{\mathrm{PI}}^{2}$ in Eq. (1). Such a removal of $V_{\mathrm{PI}}^{2}$ also reduces possible contribution of the SST trend on $V_{\max }^{2}$, because the largest SST influence is included in $V_{\mathrm{PI}}^{2}$ in terms of surface enthalpy fluxes and energy efficiency. Thus, the variability of the residual intensity $V_{m}^{2}$ could display more effects of TSS on TC development.

Because the storm-centered average better captures environmental conditions in which a TC could reach its maximum intensity than the basinwide average, Fig. 6 shows the correlation analyses between the residual $V_{m}^{\prime 2}$ and the storm-centered averaged TSS. As seen in Fig. 6, the most noticeable difference between the SSTremoving and the full-intensity analyses is just the level of significance (i.e., the $p$ values), which is larger in both the WPAC and NATL basins after SST is removed as compared to the original analyses with $V_{\max }^{2}$ (Table 4). Specifically, the $p$ values increase from 0.05 to 0.22 in the NATL basin, and from $<0.05$ to 0.76 in the WPAC basin after reducing the direct effect of SST. The negative correlation is, nonetheless, still persistent in both basins, especially for the intense TCs (category 3-5), thus supporting the inimical control of TSS on TC intensity.

We should mention again that the inverse relationship between $V_{\max }^{2}$ and TSS, even after removing SST-related

TABLE 4. As in Table 2, but for the correlation between the storm-centered average of the TSS over the entire tropospheric layer and $V_{m}^{\prime 2}$ after reducing the confounding SST contribution via $V_{\mathrm{PI}}^{2}$ as given by Eq. (4).

\begin{tabular}{lccc}
\hline \hline NATL (1975-2017) & Correlation & $p$ value & $\begin{array}{c}\text { No. of data } \\
\text { points }\end{array}$ \\
\hline Storm-centered average & -0.1306 & 0.22 & 666 \\
Storm-centered category 3-5 & -0.1133 & 0.12 & 112 \\
WPAC (1988-2017) & & & \\
Storm-centered average & -0.0101 & 0.77 & 854 \\
Storm-centered category 3-5 & -0.1309 & 0.03 & 263 \\
\hline
\end{tabular}


$V_{\mathrm{PI}}^{2}$, is by no means adequate to conclusively reveal the full functional dependence of MPI on TSS, other than a linear relation. It is possible that a higher-order regression could display some nonlinear dependence of $V_{\max }^{2}$ on TSS that Eq. (4) cannot capture. Nevertheless, the results shown in Fig. 6 are still important from the practical perspective, because they support that SST and TSS can be served as two independent predictors for statistical regression in the study of TC intensity variability, or in projections of TC potential intensity based on statistical-dynamical models (DeMaria et al. 2005).

\section{e. Tropopause height relationship}

A recent study by Ferrara et al. (2017) showed that the tropopause height variability appears to be another environmental factor that could modulate the variability of intense TCs due to possible interaction of TCs with the highly stable air in the lower stratosphere. Their statistical analysis of the tropopause height from both the NCEP and ERA-Interim reanalyses captured a negative correlation between the tropopause height (TTH) and the power dissipation index in both the NATL and WPAC basins. That is, a lower tropopause would correspond to a stronger TC intensity and vice versa. While this correlation is statistically insignificant due to the short record of intense TCs, it hints that the lower stratosphere may play some role in TC development at the high-intensity limit.

A quick examination of the results obtained in this study immediately shows that the linkage between TC intensity and TTH examined in Ferrara et al. (2017) is actually related to the relationship between TC intensity and TSS presented in previous sections. This is because the tropospheric stratification is determined not only by the temperature difference between the tropopause temperature and the surface temperature, but also by the thickness of the troposphere. Assuming the same temperature difference between the surface and the tropopause, a lower tropopause height would correspond to a less stable troposphere (i.e., smaller TSS), thus giving rise to a higher TC intensity according to Eq. (1). In this regard, the negative correlation between the tropopause height and TC intensity as shown in Ferrara et al. (2017) and the negative correlation between TSS and the TC maximum intensity demonstrated in this result are consistent with each other.

To confirm the consistency between the impacts of TTH and TSS on the TC intensity variability, we analyze in this subsection the direct relationship between TTH and TSS. Intuitively, one would expect from the physical ground that a lower TTH would imply less stable troposphere (i.e., a smaller TSS), which corresponds to higher $V_{\max }^{2}$. Thus, a positive TTH-TSS correlation is expected, based on this physical constraint.

Figure 7 shows the scatterplots between the TTH and TSS for the two basins during 1948-2017. Unlike what is expected from the consistency between the $V_{\max }-\mathrm{TTH}$ relationship in Ferrara et al. (2017) and the $V_{\max }-\mathrm{TSS}$ relationship in this study, one notices that the direct correlation between TTH and TSS is actually negative in both the NATL and WPAC basins, with a larger correlation in the WPAC basin. This negative correlation means that a lower tropopause height would correspond to a smaller environmental lapse rate, thus resulting in a more stable atmosphere and weaker TC intensity overall. Such an implication of a weaker intensity for lower TTH apparently contradicts the results found in Ferrara et al. (2017), which suggests a stronger intensity for a lower TTH.

A more careful examination of the TTH and TSS calculation shows that the seeming contradiction between the results shown in Fig. 7 and those in Ferrara et al. is in fact rooted in the influence of the covarying SST and the tropopause temperature during the 19482017 period. Note that our expectation of smaller TSS for a lower TTH is realized only if the difference between SST and the tropopause temperature is fixed. In reality, SST has a warming trend globally over the last 80 years as well established in various studies (e.g., Emanuel 2005; Bengtsson et al. 2007; Villarini and Vecchi 2013; Murakami et al. 2014; Emanuel et al. 2013). Likewise, the tropical tropopause temperature is not constant but varies with time as well (Emanuel et al. 2013; Wing et al. 2015; Ferarra et al. 2017). As such, a lower TTH does not necessarily imply a smaller TSS, because a warmer SST or colder tropopause temperature could offset the weakening of TSS and result in an overall larger TSS (i.e., a more stable troposphere). In the analyses by Ferrara et al. this first-order effect of SST is reduced by first removing the TC intensity trend associated with the warming SST trend, before correlating TTH and TC intensity.

Because of such an interference of SST and tropopause temperature in the TSS trend, we attempt to remove their direct impacts on TSS by subtracting the SST and tropopause temperature contributions using the following relationship:

$$
S^{\prime}=S-\gamma\left(\mathrm{SST}-T_{o}\right)
$$

where $\gamma$ is a regressional relationship and $T_{o}$ is the tropopause temperature calculated from the reanalysis data for each basin. The correlation between TTH and TSS is then reevaluated, using the residual TSS $S^{\prime}$ instead of $S$. 

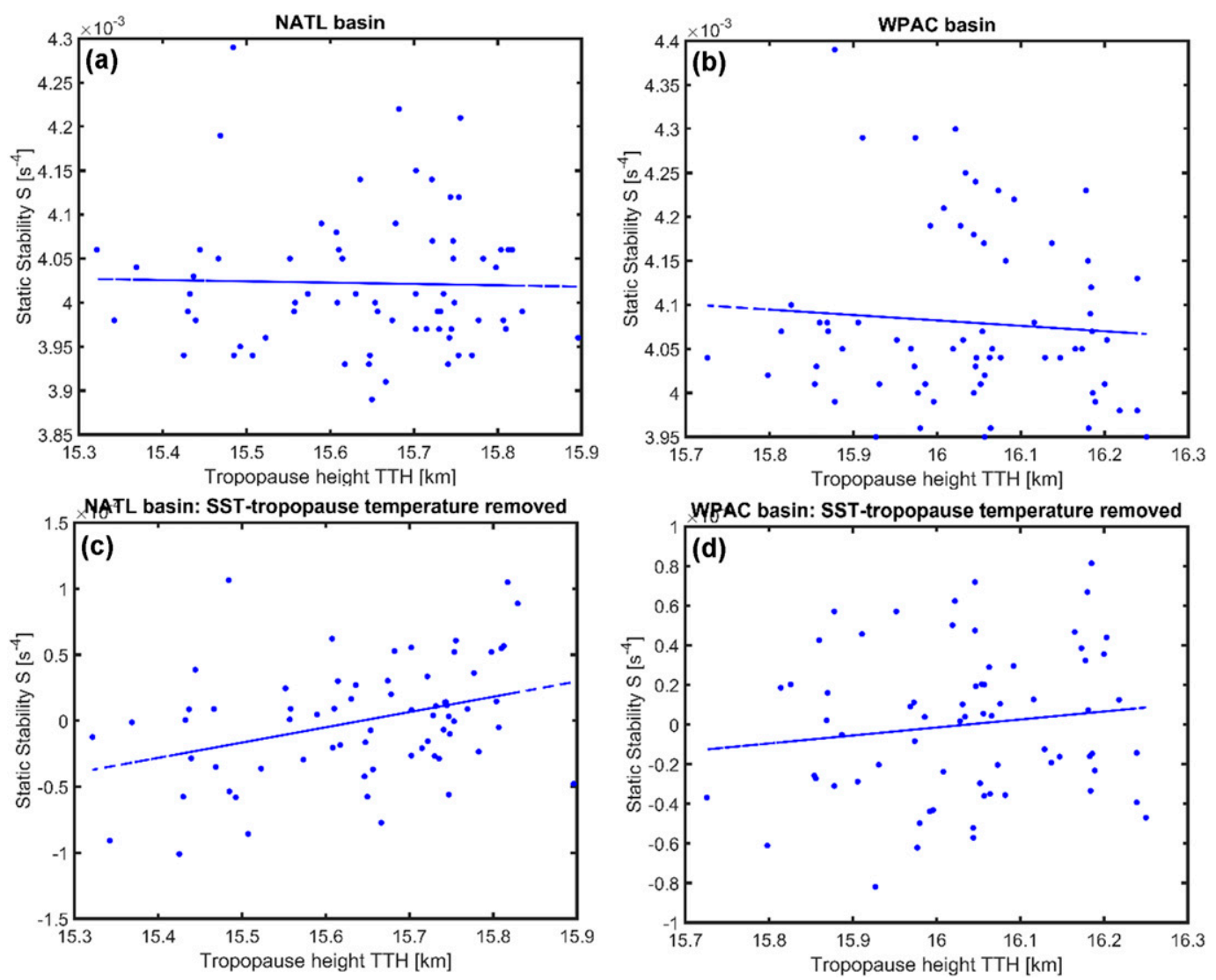

FIG. 7. Partial correlation of the tropopause height (TTH, unit: $\mathrm{km}$ ) and static stability $S$ for all TC categories in (a) the NATL basin, and (b) the WPAC basin. (c),(d) As in (a),(b), but for the residual TSS $S^{\prime}$ after reducing the direct influence of SST and the tropopause temperature as given by Eq. (4).

Figures $7 \mathrm{c}$ and $7 \mathrm{~d}$ show a similar scatterplot between $S^{\prime}$ and TTH as in Figs. $7 \mathrm{a}$ and $7 \mathrm{~b}$ after removing the contributions of SST and tropopause temperature. It is seen now that the correlation between $S^{\prime}$ and TTH becomes positive in both basins as expected. That is, a lower TTH would correspond to smaller $S^{\prime}$, and so the resulting TC intensity is stronger as expected. This positive correlation between TTH and the residual TSS indicates that the impacts of TTH and TSS variations on the TC intensity are consistent, thus reconciling the findings in Ferrara et al. (2017) and the results obtained herein.

\section{Conclusions}

In this study, the climatological relationship between TC intensity and the tropospheric static stability (TSS) was examined, based on recent results in the studies of TC development by KW7a,b and Kieu and Zhang (2018). Specifically, an empirical relationship between the TC maximum intensity and TSS was proposed to account for the effects of static stability when the strict condition of slantwise moist neutrality during TC development is not assumed. Our analyses of the tropospheric stability using the NCEP-NCAR reanalysis showed that there is a persistent negative correlation between the annually averaged TC intensity and basinwide averaged TSS, suggesting a weaker TC intensity for more stable troposphere. This negative correlation is more significant for category 3-5 TCs, particularly in the WPAC basin where the number of intense storms far outnumbers that in the NATL basin.

Additional analyses of the TC lifetime maximum intensity $\left(V_{\max }\right)$ and the storm-following environment in which TSS is averaged within an area of $2000 \mathrm{~km} \times$ $2000 \mathrm{~km}$ around each TC location strengthen the statistical significance level of the negative correlation between $V_{\max }$ and TSS. The significant negative correlation is much more apparent in the WPAC basin for TCs of category $3-5$, which supports the theoretical and modeling results from our recent studies. These results are 
robust beyond the specific NCEP-NCAR reanalysis data, as similar statistics using ERA-Interim data capture the same negative correlation in both the NATL and WPAC basins (see the appendix).

By separating the static stability in the upper and lowertropospheric layers, it was further found that it is the uppertropospheric stability that plays the more important role in TC maximum intensity variability. Such dominant impacts of the upper troposphere with a more consistent statistical significance as compared to the lower troposphere is realized in both the NATL and WPAC basins. Our other attempt to minimize the direct contribution of SST to the $V_{\text {max }}-$ TSS relationship showed a similar persistent negative correlation for both basins, thus reiterating the inimical impacts of TSS on the TC long-term intensity variability.

Given the persistency of the correlation across different reanalysis dataset and data stratification, the results obtained in this study suggest that the tropospheric static stability does have a negating impact on TC intensity beyond the assumption of strict moist neutral convection in the traditional MPI framework. These results may appear at first to be trivial from a physical perspective, as it has been well documented from previous modeling studies that a more stable troposphere would be detrimental to TC development. However, in the context of the climate variability of TC intensity, our results provide evidence on the role of the environmental stratification that has not been accounted for in previous studies. In particular, the future projection of TC potential intensity based solely on SST will overestimate the change in MPI due to the possible offset caused by more stable troposphere in a warmer climate. Thus, the tropospheric static stability needs to be properly taken into account in the studies of long-term TC intensity variability.

Despite the consistency of the statistics in both ocean basins and TC intensity metrics, several caveats of this study should be mentioned. First, the statistical relationship obtained in this study contains significant uncertainty due to the short TC data record as well as the quality of the reanalysis dataset. Along with the lack of accounting for other environmental factors such as TC movement, transitional speed, or location, most statistical analyses in this study have $p$ values beyond the typical confidence interval, especially in the NATL basin. An ideal approach should stratify the TC intensity database into different bins such that the confounding impacts of these environmental factors can be minimized. This caveat is, however, hard to address with the available data due to the limited data record, the high fluctuation of TC intensity, as well as the uncertainties in the current reanalysis datasets. Second, the dependence of TC maximum intensity on TSS is not guaranteed to be the same as the dependence of MPI on TSS. While the linear relation between $V_{\max }^{2}$ or the annually averaged intensity and TSS was captured in most analyses, how this linear relationship can be applied for the MPI-TSS relationship is unclear. This is because the lifetime maximum intensity and MPI are different in real TC development, with the former depending on many other environmental conditions that the analyses in this study could not capture. More modeling studies are, therefore, needed to quantify how much of an impact TSS can impose on the theoretical MPI limit as compared to other factors for which we wish to present in our future study.

Acknowledgments. This study was partially supported by the funding from Indiana University's Grand Challenge Initiatives and the Office of Naval Research (ONR)'s Young Investigator Award (N000141812588). The first author would like also to acknowledge the Indiana University's graduate student fellowship for her M.S. degree research. We wish to thank Dr. Chris Landsea and two anonymous reviewers for their constructive comments, which have helped improve the quality of this work substantially.

\section{APPENDIX}

\section{Sensitivity to the Reanalysis Dataset}

Given the potential problem with the NCEP reanalysis at the upper level as presented in Kossin (2015) and Emanuel et al. (2013), it is necessary to examine if the relationship between TC intensity and TSS obtained from the NCEP reanalysis is valid for other reanalysis datasets. In this regard, the European Centre for Medium-Range Weather Forecasts interim reanalysis (ERA-Interim; Dee et al. 2011) from 1979 to 2015 is used to evaluate the statistics obtained from the NCEP Reanalysis. While the ERA-Interim dataset suffers from several issues such as the larger tropical moisture (precipitation, total column water vapor) than observed after 1991, the use of this dataset could provide some complement information that the NCEP reanalysis dataset could not obtain alone.

Figure A1 shows the statistics between TC intensity and TSS similar to what was presented in sections $3 a$ and $3 b$, using the ERA-Interim dataset. One notices first a significant different characteristic of TSS obtained from the ERA-Interim reanalysis, with the TSS in the WPAC is systematically larger than that in the NATL basin. Unlike the NCEP reanalysis dataset for which TSS in both the WPAC and NATL basins are very close to each other (cf. Fig. 3), the ERA-Interim shows a difference in the tropospheric structure between the two basins for the entire 1979-2015 period. This difference in TSS is 

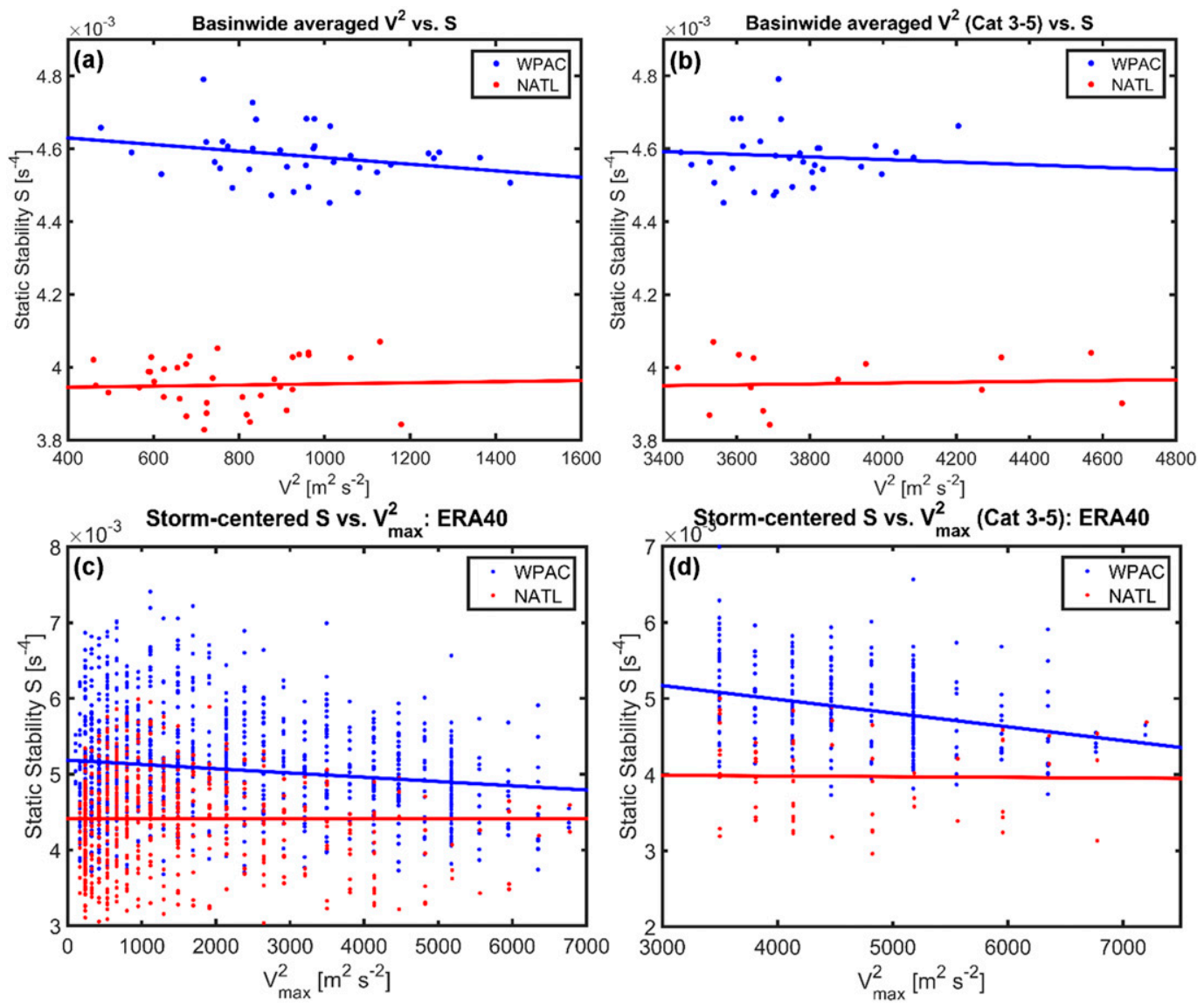

FIG. A1. (a) As in Fig. 2a, but for TSS derived from ERA-Interim during 1979-2015 period for all TC category; (b) as in (a), but for category 3-5 only; (c),(d) as in (a),(b), but for the lifetime maximum intensity $V_{\max }^{2}$ and the storm-centered average TSS during the same period 1979-2015.

also consistent with difference in the tropopause level reported in Ferrara et al. (2017).

Despite this different magnitude of TSS in the ERAInterim reanalysis, it is of interest to observe an overall higher negative correlation between TC intensity and TSS in the WPAC basin for both the basinwide and storm-centered averages. In the NATL basin, there appears, however, a slight positive correlation between TC intensity and TSS, which is not consistent with what obtained from the NCEP reanalysis (cf. Figs. 2 and 3). Although this positive correlation is not statistical significance for both the basinwide and storm-centered averages, it indicates at least that the two reanalysis datasets are most different in the NATL basin. Such inconsistency is also reflected in the fact that TSS in the NATL basin obtained from the ERA-Interim is substantially weaker than that from the NCEP reanalysis as mentioned above. Regardless of the reanalysis dataset, it is, however, evident that an inverse relationship between TC intensity and TSS is realized in the WPAC basin, thus supporting the analyses obtained from the NCEP-NCAR reanalysis.

\section{REFERENCES}

Bell, G. D., and Coauthors, 2000: Climate Assessment for 1999. Bull. Amer. Meteor. Soc., 81, S1-S50, https://doi.org/10.1175/ 1520-0477(2000)81[s1:CAF]2.0.CO;2.

Bengtsson, L., K. I. Hodges, M. Esch, N. Keenlyside, L. Kornblueh, J.-J. Luo, and T. Yamagata, 2007: How may tropical cyclones change in a warmer climate? Tellus, 59A, 539-561, https:// doi.org/10.1111/j.1600-0870.2007.00251.x.

Bister, M., and K. Emanuel, 2002: Low frequency variability of tropical cyclone potential intensity. 1. Interannual to interdecadal variability. J. Geophys. Res., 107, 4801, https://doi.org/ 10.1029/2001JD000776.

Camargo, S. J., 2013: Global and regional aspects of tropical cyclone activity in the CMIP5 models. J. Climate, 26, 9880-9902, https://doi.org/10.1175/JCLI-D-12-00549.1.

Chang, E. K. M., and Y. Guo, 2007: Is the number of North Atlantic tropical cyclones significantly underestimated prior to the availability of satellite observations? Geophys. Res. Lett., 34, L14801, https://doi.org/10.1029/2007GL030169. 
Chu, J. H., C. R. Sampson, A. S. Levine, and E. Fukada, 2002: The Joint Typhoon Warning Center Tropical Cyclone Best-Tracks, 1945-2000. Joint Typhoon Warning Center Rep. NRL/MR/754002-16, http://www.usno.navy.mil/NOOC/nmfc-ph/RSS/jtwc/best_ tracks/TC_bt_report.html.

Collins, J. M., and I. M. Mason, 2000: Local environment conditions related to seasonal tropical cyclone activity in the northeast Pacific basin. Geophys. Res. Lett., 27, 3881-3884, https://doi.org/10.1029/2000GL011614.

Dee, D. P., and Coauthors, 2011: The ERA-Interim reanalysis: Configuration and performance of the data assimilation system. Quart. J. Roy. Meteor. Soc., 137, 553-597, https://doi.org/10.1002/qj.828.

Delgado, S., C. W. Landsea, and H. Willoughby, 2018: Reanalysis of the 1954-63 Atlantic hurricane seasons. J. Climate, 31, 4177-4192, https://doi.org/10.1175/JCLI-D-15-0537.1.

DeMaria, M., M. Mainelli, L. K. Shay, J. A. Knaff, and J. Kaplan, 2005: Further improvements to the Statistical Hurricane Intensity Prediction Scheme (SHIPS). Wea. Forecasting, 20, 531-543, https://doi.org/10.1175/WAF862.1.

Dvorak, V.F., 1975: Tropical cyclone intensity analysis and forecasting from satellite imagery. Mon. Wea. Rev., 103, 420-430, https:// doi.org/10.1175/1520-0493(1975)103<0420:TCIAAF > 2.0.CO;2.

_ 1984: Tropical cyclone intensity analysis using satellite data. NOAA NESDIS Tech. Rep. 11, 52 pp.

Elsner, J. B., 2003: Tracking hurricanes. Bull. Amer. Meteor. Soc., 84, 353-356, https://doi.org/10.1175/BAMS-84-3-353.

— hurricane counts. J. Climate, 19, 2935-2952, https://doi.org/ 10.1175/JCLI3729.1.

Emanuel, K. A., 1986: An air-sea interaction theory for tropical cyclones. Part I: Steady-state maintenance. J. Atmos. Sci., 43, 585-605, https://doi.org/10.1175/1520-0469(1986)043<0585: AASITF $>2.0 . \mathrm{CO} ; 2$.

- 2000: A statistical analysis of tropical cyclone intensity. Mon. Wea. Rev., 128, 1139-1152, https://doi.org/10.1175/15200493(2000)128<1139:ASAOTC $>2.0$.CO;2.

- 2005: Increasing destructiveness of tropical cyclones over the past 30 years. Nature, 436, 686-688, https://doi.org/10.1038/ nature 03906.

— S. Solomon, D. Folini, S. Davis, and C. Cagnazzo, 2013: Influence of tropical tropopause layer cooling on Atlantic hurricane activity. J. Climate, 26, 2288-2301, https://doi.org/ 10.1175/JCLI-D-12-00242.1.

Ferrara, M. F., F. Groff, Z. Moon, K. Keshavamurthy, S. M. Robeson, and C. Kieu, 2017: Large-scale control of the lower stratosphere on variability of tropical cyclone intensity. Geophys. Res. Lett., $\mathbf{4 4}$, 4313-4323, https://doi.org/10.1002/2017GL073327.

Gilford, D. M., S. Solomon, K. A. Emanuel, and D. Rothenberg, 2017: The seasonality of tropical cyclone maximum intensity in the North Atlantic and western Pacific regions. 33rd Conf. on Hurricanes and Tropical Meteorology, Jacksonville, FL, Amer. Meteor. Soc., 262, https://ams.confex.com/ams/33HURRICANE/webprogram/ Handout/Paper338814/2018AMSTropicalMeetingPoster_v8.pdf.

,$- \ldots$, and — 2019: Seasonal cycles of along-track tropical cyclone maximum intensity. Mon. Wea. Rev., 147, 2417-2432, https://doi.org/10.1175/MWR-D-19-0021.1.

Goldenberg, S. B., C. W. Landsea, A. M. Mestas-Nunez, and W. M. Gray, 2001: The recent increase in Atlantic hurricane activity: Causes and implications. Science, 293, 474-479, https://doi.org/ 10.1126/science. 1060040 .

Gray, W. M., 1968: A global view of the origin of tropical disturbances and storms. Mon. Wea. Rev., 96, 669-700, https://doi.org/ 10.1175/1520-0493(1968)096<0669:GVOTOO > 2.0.CO;2.
Hagen, A. B., and C. W. Landsea, 2012: On the classification of extreme Atlantic hurricanes utilizing mid-twentieth-century monitoring capabilities. J. Climate, 25, 4461-4475, https:// doi.org/10.1175/JCLI-D-11-00420.1.

Hill, K., and G. Lackmann, 2011: The impact of future climate change on hurricane intensity and structure: A downscaling approach. J. Climate, 24, 4644-4661, https://doi.org/10.1175/2011JCLI3761.1.

Kalnay, E., and Coauthors, 1996: The NCEP/NCAR 40-Year Reanalysis Project. Bull. Amer. Meteor. Soc., 77, 437-471, https:// doi.org/10.1175/1520-0477(1996)077<0437:TNYRP>2.0.CO;2.

Kamahori, H. N., N. Yamazaki, N. Mannoji, and K. Takahashi, 2006: Variability in intense tropical cyclone days in the western North Pacific. SOLA, 2, 104-107, https://doi.org/10.2151/ SOLA.2006-027.

Kieu, C., 2015: Hurricane maximum potential intensity equilibrium. Quart. J. Roy. Meteor. Soc., 141, 2471-2480, https:// doi.org/10.1002/qj.2556.

_ and Q. Wang, 2017a: Stability of the tropical cyclone intensity equilibrium. J. Atmos. Sci., 74, 3591-3608, https://doi.org/ 10.1175/JAS-D-17-0028.1.

— and - 2017b: On the scale dynamics of tropical cyclone intensity. Discrete Contin. Dyn. Syst., 22B (5), 44-54, https:// doi.org/10.3934/dcdsb.2017196.

— , and D.-L. Zhang, 2018: The control of environmental stratification on the hurricane maximum potential intensity. Geophys. Res. Lett., 45, 6272-6280, https://doi.org/10.1029/2018GL078070.

— , V. Tallapragada, D.-L. Zhang, and Z. Moon, 2016: On the development of double warm-core structures in intense tropical cyclones. J. Atmos. Sci., 73, 4487-4506, https://doi.org/ 10.1175/JAS-D-16-0015.1.

Klotzbach, P. J., 2010: On the Madden-Julian oscillation-Atlantic hurricane relationship. J. Climate, 23, 282-293, https://doi.org/ 10.1175/2009JCLI2978.1.

- 2014: Prediction of seasonal Atlantic basin accumulated cyclone energy from 1 July. Wea. Forecasting, 29, 115-121, https://doi.org/10.1175/WAF-D-13-00073.1.

Knutson, T. R., and Coauthors, 2010: Tropical cyclones and climate change. Nat. Geosci., 3, 157-163, https://doi.org/10.1038/ ngeo779.

_- and Coauthors, 2013: Dynamical downscaling projections of twenty-first-century Atlantic hurricane activity: CMIP3 and CMIP5 model-based scenarios. J. Climate, 26, 6591-6617, https://doi.org/10.1175/JCLI-D-12-00539.1.

Kossin, J. P., 2015: Validating atmospheric reanalysis data using tropical cyclones as thermometers. Bull. Amer. Meteor. Soc., 96, 1089-1096, https://doi.org/10.1175/BAMS-D-14-00180.1.

_ S. J. Camargo, and M. Sitkowski, 2010: Climate modulation of North Atlantic hurricane tracks. J. Climate, 23, 3057-3076, https://doi.org/10.1175/2010JCLI3497.1.

_ , K. A. Emanuel, and S. J. Camargo, 2016: Past and projected changes in western North Pacific tropical cyclone exposure. J. Climate, 29, 5725-5739, https://doi.org/10.1175/JCLI-D-16-0076.1.

Lander, M. A., and C. P. Guard, 1998: A look a global tropical cyclone activity during 1995: Contrasting high Atlantic activity with low activity in other basins. Mon. Wea. Rev., 126, 1163 1173, https://doi.org/10.1175/1520-0493(1998)126<1163:ALAGTC> 2.0.CO;2.

Landsea, C. W., 1993: A climatology of intense (or major) Atlantic hurricanes. Mon. Wea. Rev., 121, 1703-1713, https://doi.org/ 10.1175/1520-0493(1993)121<1703:ACOIMA > 2.0.CO;2.

- 2007: Counting Atlantic tropical cyclones back to 1900. Eos, Trans. Amer. Geophys. Union, 88, 197-202, https://doi.org/ 10.1029/2007EO180001. 
_ B. B. Aarper, K. Hoarau, and J. A. Knaff, 2006: Can we detect trends in extreme tropical cyclones? Science, 313, 452454, https://doi.org/10.1126/science.1128448.

— G. A. Vecchi, L. Bengtsson, and T. R. Knutson, 2010: Impact of duration thresholds on Atlantic tropical cyclone counts. J. Climate, 23, 2508-2519, https://doi.org/10.1175/2009JCLI3034.1.

—, A. Hagen, W. Bredemeyer, C. Carrasco, D. A. Glenn, A. Santiago, D. Strahan-Sakoskie, and M. Dickinson, 2014: A reanalysis of the 1931-43 Atlantic hurricane database. J. Climate, 27, 6093-6118, https://doi.org/10.1175/JCLI-D-13-00503.1.

Lin, I.-I., and J. C. Chan, 2015: Recent decrease in typhoon destructive potential and global warming implications. Nat. Commun., 6, 7182, https://doi.org/10.1038/ncomms8182.

Maloney, E. D., and D. L. Hartmann, 2000: Modulation of hurricane activity in the Gulf of Mexico by the Madden-Julian oscillation. Science, 287, 2002-2004, https://doi.org/10.1126/ science.287.5460.2002.

Moon, Z., and C. Kieu, 2016: On the role of the tropopause height in the development of a double warm core structure in intense tropical cyclones. 32nd Conf. on Hurricanes and Tropical Meteorology, Puerto Rico, Amer. Meteor. Soc., 10A.5, https://ams.confex.com/ ams/32Hurr/webprogram/Handout/Paper293222/AMS_20Apr_zmoon.pdf.

Murakami, H., B. Wang, and A. Kitoh, 2011: Future change of western North Pacific typhoons: Projections by a 20-km-mesh global atmospheric model. J. Climate, 24, 1154-1169, https:// doi.org/10.1175/2010JCLI3723.1.

_ , T. Li, and P. Hsu, 2014: Contributing factors to the recent high level of accumulated cyclone energy (ACE) and power dissipation index (PDI) in the North Atlantic. J. Climate, 27, 3023-3034, https://doi.org/10.1175/JCLI-D-13-00394.1.

Oouchi, K., J. Yoshimura, H. Yoshimura, R. Mizuta, S. Kusunoki, and A. Noda, 2006: Tropical cyclone climatology in a globalwarming climate as simulated in a $20 \mathrm{~km}$-mesh global atmospheric model: Frequency and wind intensity analyses. J. Meteor. Soc. Japan, 84, 259-276, https://doi.org/10.2151/jmsj.84.259.

Ooyama, K., 1969: Numerical simulation of the life cycle of tropical cyclones. J. Atmos. Sci., 26, 3-40, https://doi.org/ 10.1175/1520-0469(1969)026<0003:NSOTLC $>2.0$.CO;2.

Plesca, E., S. A. Buehler, and V. Grützun, 2018: The fast response of the tropical circulation to $\mathrm{CO}_{2}$ forcing. J. Climate, 31, 9903 9920, https://doi.org/10.1175/JCLI-D-18-0086.1.

Ramsay, H. A., 2013: The effects of imposed stratospheric cooling on the maximum intensity of tropical cyclones in axisymmetric radiative-convective equilibrium. J. Climate, 26, 9977-9985, https://doi.org/10.1175/JCLI-D-13-00195.1.

Rappaport, E. N., and Coauthors, 2009: Advances and challenges at the National Hurricane Center. Wea. Forecasting, 24, 395419, https://doi.org/10.1175/2008WAF2222128.1.

Rayner, N. A., D. E. Parker, E. B. Horton, C. K. Folland, L. V. Alexander, D. P. Rowell, E. C. Kent, and A. Kaplan, 2003: Global analyses of sea surface temperature, sea ice, and night marine air temperature since the late nineteenth century. J. Geophys. Res., 108, 4407, https://doi.org/10.1029/2002JD002670.

Ryglicki, D. R., J. H. Cossuth, D. Hodyss, and J. D. Doyle, 2018: The unexpected rapid intensification of tropical cyclones in moderate vertical wind shear. Part I: Overview and observations. Mon. Wea. Rev., 146, 3773-3800, https://doi.org/10.1175/ MWR-D-18-0020.1.

Sharmila, S., and K. J. E. Walsh, 2018: Recent poleward shift of tropical cyclone formation linked to Hadley cell expansion. Nat. Climate Change, 8, 730-736, https://doi.org/10.1038/s41558018-0227-5.
Sheets, R. C., 1990: The National Hurricane Center-Past, present, and future. Wea. Forecasting, 5, 185-232, https://doi.org/ 10.1175/1520-0434(1990)005<0185:TNHCPA > 2.0.CO;2.

Shen, W., R. E. Tuleya, and I. Ginis, 2000: A sensitivity study of the thermodynamic environment on GFDL model hurricane intensity: Implications for global warming. J. Climate, 13, 109-121, https:// doi.org/10.1175/1520-0442(2000)013<0109:ASSOTT>2.0.CO;2.

Smith, S. R., J. Brolley, J. J. O'Brien, and C. A. Tartaglione, 2007: ENSO's impact on regional U.S. hurricane activity. J. Climate, 20, 1404-1414, https://doi.org/10.1175/JCLI4063.1.

Sohn, B.-J., S. Lee, E.-S. Chung, and H.-J. Song, 2016: The role of the dry static stability for the recent change in the Pacific Walker circulation. J. Climate, 29, 2765-2779, https://doi.org/ 10.1175/JCLI-D-15-0374.1.

Song, J.-J., Y. Wang, and L. Wu, 2010: Trend discrepancies among three best track data sets of western North Pacific tropical cyclones. J. Geophys. Res., 115, D12128, https://doi.org/ 10.1029/2009JD013058.

Tuleya, R. E., M. Bender, T. R. Knutson, J. J. Sirutis, B. Thomas, and I. Ginis, 2016: Impact of upper-tropospheric temperature anomalies and vertical wind shear on tropical cyclone evolution using an idealized version of the operational GFDL hurricane model. J. Atmos. Sci., 73, 3803-3820, https://doi.org/ 10.1175/JAS-D-16-0045.1.

Uhlhorn, E. W., and P. G. Black, 2003: Verification of remotely sensed sea surface winds in hurricanes. J. Atmos. Oceanic Technol., 20, 99-116, https://doi.org/10.1175/1520-0426(2003) 020<0099:VORSSS $>2.0 . \mathrm{CO} ; 2$.

Vecchi, G. A., S. Fueglistaler, I. M. Held, T. R. Knutson, and M. Zhao, 2013: Impacts of atmospheric temperature trends on tropical cyclone activity. J. Climate, 26, 3877-3891, https:// doi.org/10.1175/JCLI-D-12-00503.1.

Vigh, J. L., and W. H. Schubert, 2009: Rapid development of the tropical cyclone warm core. J. Atmos. Sci., 66, 3335-3350, https://doi.org/10.1175/2009JAS3092.1.

Villarini, G., and G. A. Vecchi, 2013: Multiseason lead forecast of the North Atlantic power dissipation index (PDI) and accumulated cyclone energy (ACE). J. Climate, 26, 3631-3643, https://doi.org/10.1175/JCLI-D-12-00448.1.

- _ —, T. R. Knutson, and J. A. Smith, 2011: Is the recorded increase in short duration North Atlantic tropical storms spurious? J. Geophys. Res., 116, D10114, https://doi.org/ 10.1029/2010JD015493.

Wang, B., and J. C. L. Chan, 2002: How strong ENSO events affect tropical storm activity over the western North Pacific. J. Climate, 15, 1643-1658, https://doi.org/10.1175/1520-0442(2002)015<1643: HSEEAT>2.0.CO;2.

_- Y. Yang, Q.-H. Ding, H. Murakami, and F. Huang, 2010: Climate control of the global tropical storm days (1965-2008). Geophys. Res. Lett., 37, L07704, https://doi.org/10.1029/2010GL042487.

Wang, S., S. J. Camargo, A. H. Sobel, and L. M. Polvani, 2014: Impact of the tropopause temperature on the intensity of tropical cyclones: An idealized study using a mesoscale model. J. Atmos. Sci., 71, 4333-4348, https://doi.org/10.1175/JAS-D-14-0029.1.

Wing, A. A., K. Emanuel, and S. Solomon, 2015: On the factors affecting trends and variability in tropical cyclone potential intensity. Geophys. Res. Lett., 42, 8669-8677, https://doi.org/ 10.1002/2015GL066145.

Zhao, M., I. M. Held, S.-J. Lin, and G. A. Vecchi, 2009: Simulations of global hurricane climatology, interannual variability, and response to global warming using a $50-\mathrm{km}$ resolution GCM. J. Climate, 22, 6653-6678, https://doi.org/10.1175/ 2009JCLI3049.1. 
Copyright of Journal of Climate is the property of American Meteorological Society and its content may not be copied or emailed to multiple sites or posted to a listserv without the copyright holder's express written permission. However, users may print, download, or email articles for individual use. 